\title{
HIV/AIDS vulnerabilities, discrimination, and service accessibility of Nigeria's youth: Summary of study findings
}

Population Council

Follow this and additional works at: https://knowledgecommons.popcouncil.org/departments_sbsr-hiv

Part of the Demography, Population, and Ecology Commons, Family, Life Course, and Society Commons, International Public Health Commons, and the Maternal and Child Health Commons How does access to this work benefit you? Let us know!

\section{Recommended Citation}

Population Council. 2014. "HIV/AIDS vulnerabilities, discrimination, and service accessibility of Nigeria's youth: Summary of study findings," fact sheet. Abuja: Population Council. 
Nigerian youth, especially females, are disproportionately affected by HIV yet remain a neglected sub-population in the response to HIV. Current HIV prevention interventions are often not youth-friendly in design and implementation. Youth therefore, fail to access these services which further worsen their vulnerability to HIV/AIDS.

\section{STUDY OVERVIEW}

This study, implemented between August 2011 and July 2012, sought to provide a comprehensive, evidence-based picture of the HIV-related issues facing Nigerian youth and the prevailing legal, policy, and programmatic responses. The study was designed to establish a basis for a sharper focus on youth within the national response to HIV.

Our researchers conducted an analytical review of the relevant literature on factors associated with HIV risk-taking and health seeking behaviors among young people aged 15-24 in Nigeria. In addition, they collaborated with leading sexual and reproductive health (SRH)/HIV-focused youth-serving nongovernmental organizations (NGOs) in Nigeria to conduct the following qualitative inquiries:

- Focus group discussions (FGDs), each made up of 6-12 participants

- In-depth interviews (IDIs) with individual perinatally infected with HIV; sex workers; orphans; married adolescents; and lesbian, gay, bisexual and transgender (LGBT) individuals. The participants represented an age- and gender-balanced population

- Key informant interviews (KIIs) with stakeholders in the arena of policies and programs regarding $\mathrm{SRH} / \mathrm{HIV}$-related issues IDFlQ $\square R X Y \backslash]$
The Population Council conducts research and delivers solutions that improve lives around the world. Big ideas supported by evidence: It's our model for global change. popcouncil.org
Secondary analyses of national HIV/SRH-related survey datasets, including the National HIV/AIDS and Reproductive Health Survey 2007; the Nigerian Demographic and Health Survey (DHS) 2008; and the Integrated Biological and Behavioral Surveillance Survey 2010 were also performed. Multivariate analyses using logistic regression were also conducted on datasets.

\section{FACTORS ASSOCIATED WITH SEXUAL RISK AND HEALTH- SEEKING BEHAVIORS AMONG YOUTH}

\section{Risky sexual behavior}

Being female (compared with being male), and residing in an urban location (compared with rural) was significantly associated with sexual debut before or at age 15. The likelihood of having an early sexual debut however reduced with increasing educational status and household wealth.

FIGURE 1: AMONG RESPONDENTS AGED 15-24, PERCENTAGE REPORTING FIRST SEX ON OR BEFORE AGE 15, BY LOCATION AND SEX

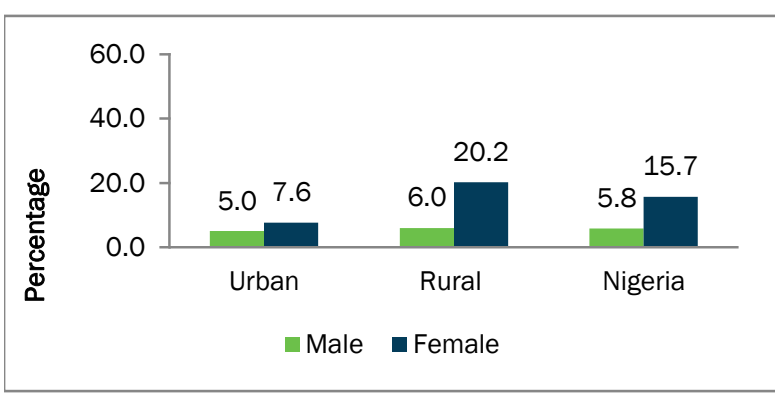

Data Source: DHS 2008

\section{Condom use during last sex among youth in multiple sexual partnerships}

Compared to their male counterparts, female youth with multiple sexual partners were significantly less 
likely to use condoms during their last sexual intercourse. Also, though, educational status was associated with greater likelihood of engaging in multiple sexual partnerships, it was also associated with greater use of condoms during such risky sex, compared with those without education.

FIGURE 2: AMONG RESPONDENTS WHO WERE SEXUALLY ACTIVE IN THE PAST 12 MONTHS, PERCENTAGE REPORTING HAVING MULTIPLE SEXUAL PARTNERS BY AGE AND SEX

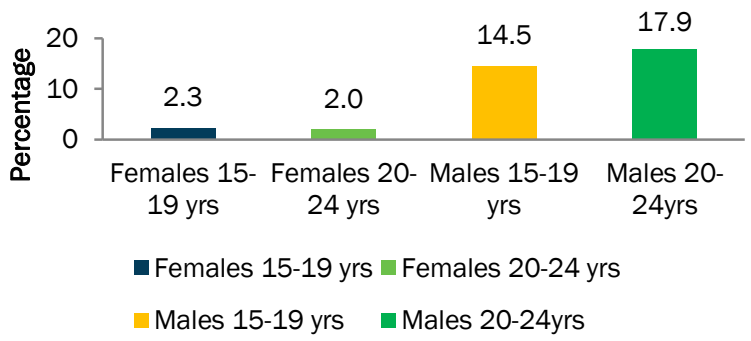

Data Source: DHS 2008

\section{Comprehensive knowledge}

Compared with youth aged 15-19 years, those aged 20-24 years were slightly more likely to have comprehensive knowledge of HIV. Female youth were also less likely to have comprehensive HIV knowledge compared to their male counterparts. Educational status and wealth were significantly positively associated with comprehensive knowledge.

FIGURE 3: PERCENTAGE OF RESPONDENTS REPORTING EVER BEING TESTED FOR HIV AND HAVING RECEIVED THE RESULTS, BY AGE AND SEX

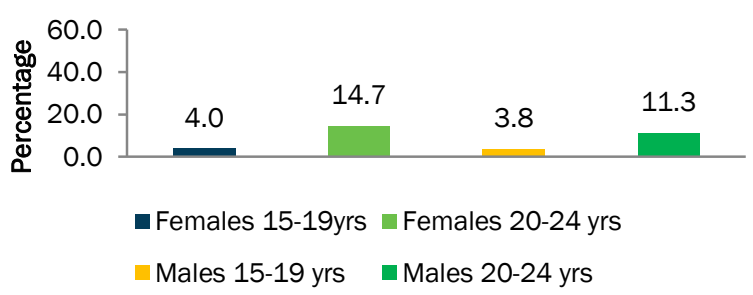

Data Source: DHS 2008

\section{Uptake of HIV testing}

Uptake of HIV testing among young people in Nigeria remains relatively low (ranging from 3.8-14.7 percent). Generally, the proportions of young women and men that reported ever seeking and receiving HIV-test results were roughly equal. Among the young people of both sexes and age groups (15-19 and 20-24), young women aged 20-24 reported the highest rate of obtaining an HIV test and receiving the results (14.7 percent) while young males aged 15-19 reported the lowest rate of obtaining an HIV test and receiving the results (3.8 percent).

\section{HIV YOUTH-FOCUSED RESPONSES AT THE INDIVIDUAL, INSTITUTIONAL, AND POLICY LEVELS}

\section{Individual level}

At the individual level, the qualitative inquiries showed that most young people considered SRH to be a significant need among youth. Despite their consideration of SRH as a priority, youth overwhelmingly felt disempowered to adequately respond to their HIV and SRH vulnerabilities because of inadequate knowledge, issues with service providers and set-up of services, and livelihood struggles.

\section{"Because there are so many things basically young people need especially their sexual health needs, there are so many things attached to it. But these health care providers, they don't want to know that. Once they see a young girl of 15 or 16 years going to health centre to get condom, they will like, the way they will look at her, that it's not for her, she is so wayward and so they don't help matters by their attitude" (IDI, Young man who has sex with men [MSM]).}

Respondents often mentioned service-provider issues such as stigmatizing attitudes and a lack of confidentiality and competence as deterrents to young people's seeking HIV and SRH services, especially in public health facilities. Limited real involvement exists in the planning, delivery (beyond peer information education, and communication [IEC]), and the management of programs and services.

\section{Institutional and policy levels}

Institutional responses continue to fall short of the needs and expectations of young people in the areas of HIV and SRH education and access to youth-friendly services, especially for the most vulnerable groups. The failures of institutional responses can be tied to the broader issue of denial and lack of openness about youth sexuality.

\footnotetext{
"Because everyone thinks that when you talk about sex, and if we go into the depth of it, we are going to get the children corrupt. So they don't want to go too far." (FGD male and female youth)
} 
Participants stated that sexuality education in primary and secondary schools only covers a narrow set of topics, mostly limited to abstinence. Condom use, family planning, and HIV counseling and testing (HCT) appear not to be taught, yet study participants viewed them as important in taking preventative action.

For out-of-school-youth, HIV and SRH information is obtained through community channels such as community outreach activities, peer education, and seminars which may only reach a very small proportion of such youth.

"Yes, for me it’s (sexuality education) just
for the students...you will have access,
information and all that... because I think
most of them on the street, don't really
know anything about it, they find it very
difficult to talk about. If you kind of
mention condom, in their presence, they
feel shy...so they don't really have...like
60 percent are not aware." (FGD, male
and female youth)

Interviews with key stakeholders and program managers reveal that few high-quality SRH and HIV policies exist for youth, but inadequate resourcing (funding, infrastructure, personnel, and supplies) of programs and services, especially for rural and poor urban youth, out-of-school youth, and young key populations, severely limits their overall impact.

"Everybody speaks to the importance of
young people, but the truth of the matter
is, how much of that money gets
allocated to the issues that would make
a difference in the epidemic amongst
young people? The money is not
appropriately allocated." (KII, Head of
youth focused NGO)

\section{CONCLUSION AND RECOMMENDATIONS}

This study highlights salient gaps and deficiencies in HIV-prevention programming among youth in Nigeria. Nigerian youth continue to be a vulnerable group. The imbalance between high-risk sex, condom use in highrisk sex, and uptake of HIV testing raises concern for HIV prevention.

This young population should have access to comprehensive SRH services and youth-focused sexuality education that goes beyond abstinence-only messages.
Prevention programs aimed at delaying sexual debut are important in the Nigerian context and should focus on both boys and girls and take into account the roles of poverty and sexual coercion in determining the sexual experiences of young men and women.

Health-care providers, who are supposed to give succor to youth, become hostile and provide a concomitant health-care environment that is not sensitive to the needs of young people who require SRH services. There is, thus, a need to sensitize all cadres of health staff to be youth-friendly. Health-care settings should be open, accessible, and welcoming to youth.

Evidence-based advocacy needs to be targeted at policymakers and donors to drive greater attention to the youth dimensions of the HIV epidemic, especially in relation to neglected but vulnerable categories of youth such as MSM, sex workers, married adolescents, and street children.

The National AIDS Control Agency (NACA) must live up to its oversight function in ensuring that young people are not neglected in national HIV policies and programs Government needs to increase funding and demonstrate ownership and sustainability of youthbased HIV programs.

Innovative operations research is called for to better understand how to increase the meaningful involvement of young people in the conception, planning, and implementation of SRH and HIV/AIDS policies and programs. 